\title{
Quais 05 suplementos alimentares mais utilizados?
}

\section{What's the food's supplement more used?}

\author{
Alex Bisotto Ferreira', Valderi Abreu de Lima², William Cordeiro de Souza', \\ Luis Paulo Gomes Mascarenhas ${ }^{3}$, Neiva Leite ${ }^{2}$ \\ Universidade do Contestado (UnC), Rio Negrinho, SC, Brasil. \\ unniversidade Federal do Paraná (UFPR), Curitiba, PR, Brasil. \\ Universidade Estadual do Centro-Oeste (Unicentro), Chopinzinho, PR, Brasil.
}

Recebido em: 31/03/2016 / Aceito em: 25/04/2016

valderiabreulima@hotmail.com

\section{RESUMO}

O consumo de suplementos alimentares tem sido muito utilizado e difundido por praticantes de atividade física, em especial a musculação, bem como, por pessoas com objetivos de melhora em desempenho, redução de gordura corporal, aumento de massa muscular entre outros. Esta pesquisa tem como objetivo revisar sobre quais os suplementos alimentares são utilizados na atualidade e destacar o mais utilizado. A fonte dos dados é uma pesquisa bibliográfica realizada em média dos últimos 15 anos, foram examinados 232 estudos, sendo selecionados 48 . Os suplementos alimentares discutidos nesse artigo foram: Carboidratos, vitaminas e minerais, I-carnitina, creatina, proteínas e aminoácidos. 0 principal motivo para a utilização de suplementos foi o aumento de massa muscular, predominantemente indicado por professores, instrutores e treinadores. Apesar da grande variedade, os suplementos mais utilizados são as proteínas e aminoácidos e, na maioria dos casos, com o intuito de aumentar a massa muscular e melhorar sua recuperação. Entretanto, os suplementos proteicos devem ser utilizados com cautela, pois o uso excessivo pode provocar riscos à saúde.

Palavras-Chave: Suplementos alimentares; Recursos ergogênicos; Academia.

\section{ABSTRACT}

The consumption of dietary supplements has been widely used and disseminated by practitioners of physical activity, especially weight training for people with improvement objectives in performance, reducing body fat, muscle mass increase and others. This research aims to review about what dietary supplements are used today, and highlight the most used. The source of data is a literature survey on average the last 15 years, were examined 232 studies, being selected 48. The dietary supplements discussed in this article are: carbohydrates, vitamins and minerals, l-carnitine, creatine, protein and amino acids. The main reason for the use of supplements has been the increase in muscle mass, predominantly indicated by teachers, instructors and coaches, despite the great variety, the most widely used supplements are proteins and amino acids, and in most cases in order to increase muscle mass and improve recovery. However, protein supplements should be used with caution, because excessive use can cause health risks.

Keywords: Dietary supplements; Ergogenic resources; Academy.

\section{INTRODUÇÃO}

Há muito tempo, médicos, treinadores, esportistas buscam de forma incessável a melhora do rendimento, por meio de substâncias milagrosas que possam suprir as necessidades muitas vezes ambiciosas dos atletas, ou simplesmente praticantes de atividades físicas. ${ }^{1}$

Atualmente, a alimentação da população em geral é quase que totalmente industrializada; na maioria das vezes com alimentos não saudáveis. Contudo, devido à falta de tempo e a facilidade, adquirir alimentos industrializados têm-se tornado frequente no dia a dia das pessoas, inclusive o uso de suplementos alimentares.

Ao contrário do que muitas pessoas pensam, os suplementos não são recomendados somente para quem procura rendimento de alto nível, a nutrição diária também pode ser melhorada com os benefícios da suplementação para melhor qualidade de vida das pessoas, levando em conta a riqueza de seus nutrientes, os quais não produzem calorias vazias como um 
achocolatado rico em açúcar, por exemplo. ${ }^{2}$

As academias estão sendo muito procuradas por pessoas que desejam emagrecer, melhorar o rendimento, aumentar massa muscular e melhorar a qualidade de vida. ${ }^{3,4}$ Com o aumento da procura por academias e pela prática de atividades física, aumentou a necessidade das pessoas em seguir uma alimentação mais equilibrada, adequando todos os nutrientes: gordura, proteínas, carboidratos, vitaminas, minerais, fibras e água ${ }^{5}$. Levando tudo isso em consideração, o mercado de suplementos alimentares vem disponibilizando para essa área, recursos para os mais diversos objetivos, sejam eles: melhora na recuperação muscular, perda de peso, aumento de peso, reduzir riscos de doenças, acréscimo na resistência, ou benefício no rendimento esportivo. ${ }^{6}$

O tema é abordado com o intuito de obter conhecimento sobre os suplementos alimentares, quais os mais utilizados e quem faz a indicação destes produtos? Esta revisão proporciona para usuários, profissionais da área e empresas no ramo de suplementação alimentar, mais conhecimento acerca da suplementação alimentar e pode contribuir para melhorar a informação, indicação ou produção específica. O objetivo geral da pesquisa é identificar quais os suplementos alimentares mais utilizados.

\section{MÉTODO}

A pesquisa de revisão de caráter descritiva foi realizada por meio de artigos científicos publicados nos últimos 15 anos, utilizando, em várias combinações, os seguintes termos de pesquisa: suplementos alimentares, alimentos, whey protein, atividade física e esporte. A pesquisa bibliográfica incluiu consensos, editoriais, artigos originais e artigos de revisão, nas línguas inglesa e portuguesa. Inicialmente, os artigos foram selecionados por meio de seus títulos e resumos, posteriormente os artigos foram lidos na íntegra e incluídos os que possuíram as seguintes informações: Consumo de suplementos alimentares em academia, quais suplementos mais utilizados, qual o grupo que mais utiliza e por quem foi indicado.

Foram excluídos da revisão artigos escritos em outros idiomas, cujo título ou resumo não tivesse relação com o objetivo da revisão. Inicialmente, foram selecionados 232 estudos, após a leitura dos títulos e resumos, foram excluídos 184 artigos que não estavam de acordo com o objetivo do estudo, restando então 48 que preencheram os critérios de inclusão, que foram analisados na íntegra e incluídos neste estudo.

\section{Suplementos alimentares}

Os suplementos nutricionais são alimentos que servem para complementar a dieta diária de pessoas saudáveis com certos nutrientes e calorias, quando a dieta por si só não consegue suprir as necessidades diárias, ou quando há a necessidade específica de algum nutriente. ${ }^{7}$ Os suplementos alimentares são divididos em suplementos ergogênicos, os que ajudam, melhoram o rendimento e desempenho do atleta. ${ }^{8} \mathrm{Su}$ plementos termogênicos, que aumentam a temperatura corporal, auxiliando no gasto calórico e redução de apetite entre outros fatores emagrecedores, tais como auxiliar na metabolização da gordura, transformando em ácido graxo para ser utilizada como fonte de energia. ${ }^{9}$ Suplementos anabólicos que são suplementos alimentares, também são agentes anabólicos, como por exemplo, o BCAA (Branched-chain amino acids), Whey protein e glutamina. $^{10,11}$

\section{Carboidratos}

O carboidrato é uma das principais fontes de energia para o organismo humano, em exercícios prolongados os níveis de glicogênio muscular são reduzidos acentuadamente. É importante a sua manutenção em níveis adequados para melhor rendimento nos exercícios e sua reposição pode ser feita por meio da suplementação, principalmente em atividades intensas e de longa duração. ${ }^{12}$

A quantidade de glicogênio consumida durante a atividade física depende da duração e da intensidade do exercício, em provas longas, por exemplo, é recomendada a ingestão de 7 a $8 \mathrm{~g} / \mathrm{kg} / \mathrm{dia}$ e 30 a $60 \mathrm{~g}$ de carboidrato para cada hora de exercício físico, com o intuito de evitar a hipoglicemia a qual levará a fadiga. Após a realização de exercícios muito exaustivos é recomendado a ingestão de 0,7 a $1,5 \mathrm{~g} / \mathrm{kg}$ de carboidrato em um período de até 4 horas após o exercício, sendo suficiente para realizar a ressíntese de glicogênio. É estimado que a ingestão de carboidratos diários seja 60 a $70 \%$ do consumo calórico total. ${ }^{12}$

Em casos no qual é muito difícil conseguir a ingestão adequada de carboidratos, devido a diversos fatores, indicam-se suplementos a base de carboidratos como a maltodextrina, por exemplo, que é um dos carboidratos mais utilizados por praticantes de exercícios. ${ }^{13} \mathrm{~A}$ maltodextrina foi o carboidrato citado por $59 \%$ dos entrevistados na pesquisa realizada por Domingues e Martins. ${ }^{14}$

\section{Vitaminas e sais minerais}

As vitaminas são componentes presentes naturalmente em alimentos e são responsáveis pela ação de atividades enzimáticas ao organismo humano, são classificadas como micronutrientes, diferente dos carboidratos, proteínas e gorduras que são macronutrientes. ${ }^{15}$ As vitaminas são lipossolúveis, ou seja, são solúveis em gordura, e hidrossolúveis, que são solúveis em água. As vitaminas lipossolúveis são as vitaminas A, D, E e K, enquanto as hidrossolúveis são as vitaminas do complexo B (tiamina, riboflavina, niacina, ácido pantatênico, piridoxina, biotina, ácido fólico, cianocobalamina) e também a vitamina $C$. Atletas que se descolam de climas temperados para climas quentes podem se beneficiar do uso das vitaminas $B$ e $C$, por elas facilitarem os fenômenos de adaptação do organismo. ${ }^{16}$ Porém, para atletas que desejam melhorar a aclimatização e adaptação com rendimento desportivo em altitudes pode se beneficiar da suplementação com vitamina E. Alguns suplementos vitamínicos em altas dosagens, ou seja, superiores ao recomendado podem causar distúrbios orgânicos como, por exemplo, alterações neurológicas. ${ }^{15} \mathrm{~A}$ deficiência de vitaminas pode causar aumento de sensibilidade muscular ao esforço físico, fadiga e redução de rendimento. Não é recomendado o uso de suplementos vitamínicos se a pessoa fizer uma alimentação balanceada, pois acredita-se que o uso de altas doses não acresce no rendimento esportivo. ${ }^{15}$ 
No estudo realizado por De Rose et al., ${ }^{16} 42,47 \%$ dos indivíduos pesquisados consumiam vitaminas e $23,28 \%$ consumiam sais minerais, uma boa parcela dos pesquisados. Em outro estudo realizado por Domingues e Martins ${ }^{14}$ foi observado que $57,5 \%$ das pessoas entrevistadas relataram o consumo de vitaminas e minerais como um dos suplementos utilizados. Porém, na maioria dos estudos pesquisados, as vitaminas e minerais não foram classificados como os suplementos mais utilizados, ficando em outras colocações não como a primeira. O maior número de indivíduos que utilizavam vitaminas e minerais em estudo realizado por Rocha e Pereira $^{3}$ foram os praticantes de ginástica e em segundo lugar ficaram os praticantes de musculação.

\section{L-carnitina}

A L-carnitina é um aminoácido muito utilizado como suplemento termogênico por praticantes de atividades físicas principalmente em academias, com o objetivo de emagrecimento, pois a I-carnitina atua no metabolismo dos ácidos graxos de cadeia longa, no intuito de utilizar mais gordura como fonte de energia. Para que a gordura seja utilizada pelo organismo como fonte de energia, ela passa por diversas alterações, primeiro sendo transformada em ácidos graxos e glicerol, o glicerol é metabolizado pela mesma via da glicose, a via glicolítica, porém o ácido graxo é mais complexo, passa por diversas reações até serem metabolizados dentro das mitocôndrias, a L-Carnitina carrega estas moléculas de gordura até a mitocôndria para serem oxidadas. ${ }^{11}$

A utilização de I-carnitina no meio esportivo, estético e no controle da obesidade vem sendo muito difundida, porém seus efeitos como redutor de gordura corporal ainda são incertos, pois não há comprovação científica suficiente. ${ }^{17}$

Em diversos estudos foram verificados a utilização de I-carnitina, mas não como suplemento mais utilizado, em estudo realizado por Pereira e $\mathrm{Cabral}^{18}$ a I-carnitina ficou como última colocada na classificação dos suplementos mais utilizados, com apenas $8 \%$ de utilização pelas pessoas praticantes de musculação de uma academia da cidade de Recife. Em outro estudo realizado por Pereira, Lajolo e Hirschbruch, ${ }^{19}$ também foi encontrado resultado onde poucas pessoas utilizavam um suplemento queimador de gordura.

\section{Creatina}

A creatina é um suplemento que vem sendo utilizada como suplemento nutricional por pessoas que desejam maior intensidade e força em seus treinamentos, ela é uma opção para quem deseja isso e aumento de massa muscular. Porém, a creatina como recurso ergogênico não é indicada para exercícios de longa duração, não encontrando nenhum suporte na literatura sobre tal efeito benéfico nesse aspecto. ${ }^{20}$ Ela pode ser indicada para indivíduos vegetaríamos ou pessoas que consomem poucas carnes, para complementar a alimentação. Somente é indicado o uso para atletas que necessitam de energia de alta intensidade e curta duração, os quais utilizam do fosfagênio muscular como fonte predominante de energia. ${ }^{12}$

Ela também é um dos suplementos mais utilizados por não atletas praticantes de atividades físicas, em especial a musculação, e um dos suplementos com mais comprovação científica sobre sua eficácia. ${ }^{20}$

\section{Proteínas e Aminoácidos}

As proteínas são um conjunto de vários aminoácidos que são utilizados no aumento de massa muscular e na reparação de diversos tecidos do organismo humano. ${ }^{1}$ As necessidades protéicas de atletas têm recebido atenção especial dos investigadores nas últimas décadas por fazer parte essencial no reparo de microlesões musculares decorrentes da prática esportiva. ${ }^{12}$

Existem vários protocolos de quantidades de proteínas que devem ser ingeridas de acordo com o peso corporal, uma delas para atletas é de 1,6 a 2,0 g/ $\mathrm{kg} /$ dia. ${ }^{22}$ Existem também quantidades mais específicas de acordo com o objetivo, como por exemplo, para o aumento de massa muscular pode-se utilizar quantidades entre 1,6 a 1,7 g/ kg/dia. Para atletas que almejam melhora na resistência quantidades entre 1,2 a 1,6 gramas por quilograma corporal ao dia são aceitáveis. Os atletas devem ter consciência de que o excesso de consumo de proteínas não significa um excesso no aumento de massa muscular, pois existe um limite no acúmulo de proteína nos tecidos. ${ }^{12}$ Entretanto, para indivíduos sedentários a ingestão pode ser de 0,8 a 1,0 g/ $\mathrm{kg} / \mathrm{dia}$, pois praticantes de atividades físicas necessitam de maiores quantidades de proteínas do que pessoas sedentárias. O consumo de proteínas e aminoácidos, após os exercícios físicos, favorecem a síntese protéica muscular e recuperação. ${ }^{23-26}$

A ingestão de proteínas logo após os exercícios físicos juntamente com a ingestão de uma fonte de carboidratos reduz a degradação protéica e favorece ainda mais o aumento de massa muscular do que a ingestão de apenas proteína. A dose recomendada é de acordo com a ingestão calórica e protéica total do dia, para o pós-treino seria na porção e $1 \mathrm{~g}$ de proteína para $2 \mathrm{~g}$ de carboidratos, ou seja, se ingerir $10 \mathrm{~g}$ de proteínas deveria ingerir $20 \mathrm{~g}$ de carboidratos, lembrando que o aumento de massa muscular é dependente do estímulo do treinamento e da necessidade que este causa, não somente da ingestão proteica. ${ }^{12}$ A tabela 1 demonstra os principais motivos citados nos artigos como objetivo ou justificativa do uso de suplementos.

Tabela 1 - Principais motivos citados para justificar o uso de suplementos alimentares em geral.

\begin{tabular}{lcc}
\hline Aumento de Massa Muscular/Peso corporal & 21 & $43,75 \%$ \\
Aumento de energia & 8 & $16,66 \%$ \\
Compensar dieta & 2 & $4,16 \%$ \\
Perder peso & 3 & $6,26 \%$ \\
Saúde & 7 & $14,59 \%$ \\
Hidratação & 2 & $4,16 \%$ \\
Performance & 5 & $10,42 \%$ \\
\hline
\end{tabular}

Em um estudo, 34,7\% dos entrevistados estudados declaram o uso de suplementos alimentares com o objetivo de aumento de massa muscular. O mesmo percentual $(34,7 \%)$ de quem declarou utilizar com para aumento de energia e melhora da performance, as outras pessoas pesquisadas declararam o uso com o objetivo de garantir a saúde, e a minoria com 4,1\%, utilizam na prevenção de doenças. ${ }^{27}$

Observou-se, em vários estudos, que o maior 
percentual de suplementos dietéticos utilizados pela população em geral é destinado para o aumento de massa muscular. ${ }^{28-32} \mathrm{Em}$ uma colocação o primeiro lugar é para quem deseja aumentar massa muscular, em segundo lugar seria com o objetivo de hidratar-se, matar a sede, e em terceiro com a finalidade de melhora de performance. ${ }^{33}$

As mulheres, especialmente devido ao grande valor demonstrado pela busca de um corpo magro e físico atlético, se exercitam para controlar o peso e melhorar o condicionamento físico. ${ }^{34}$ Outro ponto que foi avaliado no presente estudo foi quem são as pessoas que indicam o uso de suplementos alimentares? Na tabela 2 estão os resultados encontrados.

Tabela 2 - Quem tem indicado o uso de suplementos alimentares.

\begin{tabular}{lcc}
\hline Professor, Instrutor, Treinador & 29 & $60,42 \%$ \\
Nutricionista & 7 & $14,58 \%$ \\
Médico & 5 & $10,42 \%$ \\
Mídia & 2 & $4,16 \%$ \\
Amigos & 3 & $6,26 \%$ \\
Vendedor & 2 & $4,16 \%$ \\
\hline
\end{tabular}

Apesar de tantas fontes de indicação ainda há pessoas que fazem o uso de suplementos alimentares sem qualquer indicação profissional e a minoria recebe o acompanhamento de profissionais qualificados. ${ }^{35} \mathrm{O}$ mesmo foi observado por Araújo e Soares, ${ }^{40}$ onde $54 \%$ dos pesquisados relataram utilizar suplementos sem indicação profissional, por vários motivos, que foram desde recomendações de amigos, mídia ou parentes, somente os outros $46 \%$ que faziam o uso com indicação.

Os profissionais especializados em prescrever dietas, o uso de suplementação alimentar, elaboração de programas alimentares e avaliar as necessidades dietéticas dos praticantes de atividades físicas são os nutricionistas e médicos, médicos de preferência os que têm especialização em medicina esportiva, de acordo com a lei $\mathrm{n} 18.234$ de 17 de setembro de 1991, artigo 41, VII (CFN). Mesmo em academias que têm profissionais de nutrição no quadro de funcionários, a troca de informação de alunos com instrutores, professores e entre os próprios alunos é muito grande ${ }^{5}$. As pessoas que mais indicam os suplementos são os professores. $3,19,33,36,37$ A tabela 3 relaciona os suplementos alimentares mais utilizados citados nos artigos.

Dentre os suplementos alimentares, existem várias opções para os indivíduos escolherem, de acordo com seus objetivos. ${ }^{43,48}$ Os suplementos que mais foram encontrados nos estudos são compostos protéicos, como whey protein, albumina, e outros tipos de proteínas, aminoácidos, vitaminas, sais minerais, L-carnitina, creatina e bebidas energéticas. ${ }^{1,12,15}$

Muitos suplementos são centrados apenas em alimentos esportivos especialmente formulados, como por exemplo, barras de proteínas, géis repositores energéticos ou protéicos, bebidas esportivas entre outros que são considerados na sua maioria macronutrientes e outros formulados com concentrações de vitaminas e minerais e são classificados como micronutrientes. ${ }^{38,44}$

Em um estudo realizado por Pereira e Cabral ${ }^{18}$ foi demonstrada que a maioria dos praticantes de musculação utilizava suplementos à base de proteínas e aminoácidos, eles concluíram que, provavelmente, era pelo fato dos usuários acreditarem que o consumo dos mesmos aumentaria a massa muscular, corroborando com tal estudo, porém, realizados em lugares diferentes e regiões diferentes do país foi encontrado resultado semelhante nas pesquisas os quais as pessoas também utilizavam predominantemente suplementos hiperprotéicos, com o pensamento de que quanto mais proteína ingerida maior o aumento de massa muscular. ${ }^{47}$

A interpretação dos dados referentes ao uso de suplementos alimentares é dificultada por inúmeras variáveis que podem confundir a análise do presente estudo. Existem grandes variações de produtos e doses utilizadas, normalmente a necessidade de utilização dos suplementos não é avaliada. Novos estudos devem ser realizados com o intuito de analisar o uso de suplementos alimentares, bem como seus efeitos e possíveis efeitos colaterais.

\section{CONSIDERAÇÕES FINAIS}

Existem muitos tipos de suplementos alimentares para diversos objetivos; alguns suplementos ainda carecem de estudos para comprovar a real eficácia e efeitos adversos. O principal motivo para a utilização de suplementos foi o aumento de massa muscular, predominantemente indicado por professores, instrutores e treinadores. Os profissionais da área da saúde precisam orientar que os suplementos podem ser utilizados para facilitar os ajustes nutricionais de atletas e de indivíduos que não possuem disponibilidade de efetuar uma dieta balanceada diariamente, o que significa ter o objetivo de complementar a nutrição em casos específicos e não substituir a alimentação diária. Apesar da grande variedade, os suplementos mais utilizados são as proteínas e aminoácidos e, na maioria dos casos, com o intuito

Tabela 3 - Suplementos mais utilizados.

\begin{tabular}{ll}
\hline Proteína/Aminoácidos & Albumina, Whey Protein, Aminoácidos de cadeia ramificada (BCAA), Arginina, lisina, ornitina, triptofano e aspartatos. \\
\hline Carboidratos & Maltodextrina, Dextrose, Carboidratos em gel e Sacarose. \\
\hline Gorduras & Ácidos graxos Ômega-3 e Triglicerídeos de cadeia média. \\
\hline Vitaminas & Antioxidantes, Ácido pantotênico, Tiamina (B1), Ácido fólico, Riboflavina (B2), B12, Niacina, Ácido ascórbico (C), \\
& Piridoxina (B6) e Vitamina E. \\
\hline Minerais & Cálcio, Fosfato, Cromo, Selênio, Ferro, Zinco e Magnésio \\
\hline Extratos de plantas & Fitosteróis anabólicos e Ginseng. \\
\hline $\begin{array}{l}\text { Suplementos industrialmente } \\
\text { formulados }\end{array}$ & HBM (beta-hidroxi-beta-metilbutirato). \\
\hline Termogênicos & L-carnitina e Cafeína. \\
\hline
\end{tabular}


de aumentar a massa muscular e melhorar sua recuperação. Entretanto, os suplementos proteicos devem ser utilizados com cautela, pois o uso excessivo pode provocar riscos à saúde.

\section{REFERÊNCIAS}

1. Philippi JMS. O uso de suplementos alimentares e hábitos de vida de universitários: o caso da UFSC. [Tese de Doutorado]. Programa de Pós Graduação em Engenharia de Produção. Universidade Federal de Santa Catarina; 2004.

2. Peres R. Viva em dieta, viva melhor: Aplicações práticas de nutrição. $2^{a}$ ed.. São Paulo: Phorte; 2013.

3. Rocha LP, Pereira MVL. Consumo de suplementos nutricionais por praticantes de exercícios físicos em academias. Rev Nutr 1998;11(1):76-82.

4. Carvalho JR, Hirschbruch MD. Consumo de suplementos nutricionais por freqüentadores de uma academia de ginástica de São Paulo. I Prêmio Maria Lúcia Ferrari Cavalcanti. Anais. São Paulo, Conselho Regional de Nutricionistas $-3^{a}$ Região; 2000.

5. Almeida C, Radke TL, Liberali R, Navarro F. Avaliação do conhecimento sobre nutrição esportiva, uso e indicação de suplementos alimentares por educadores físicos nas academias de Passo Fundo/RS. Rev Bras Nutrição Esportiva 2009;3(15):232-40.

6. Maughan RJ, Burke LM. Nutrição Esportiva. Porto Alegre: Artmed; 2004.

7. Albuquerque MM. Avaliação do consumo de suplementos alimentares nas academias de Guará - DF. Rev Bras Nutrição Esportiva 2012;6(32):112-7.

8. Wilmore JH, Costill DL. Physiology of sport and exercise. 2. ed. United States: Human Kinetics; 1999.

9. Santos JP, Von Der Heyde MED, Niehues LP. Perfil alimentar de praticantes de musculação para hipertrofia muscular. Departamento de Nutrição da Universidade Federal do Paraná; 2002.

10. Biscaia I. Drogas Anabolizantes. Rio de Janeiro. Grupo de Estudos avançados em Saúde e Exercício (GEASE); 2004.

11. Linhares TC, Lima RM. Prevalência do uso de suplementos alimentares por praticantes de musculação nas academias de Campos dos Goytacazes/RJ, Brasil. Vértices 2006;8(1/3):10222. DOI: 10.5935/1809-2667.20060008.

12. Hernandez AJ, Nahas RM. Modificações dietéticas, reposição hídrica, suplementos alimentares e drogas: comprovação de ação ergogênica e potenciais riscos para a saúde. Rev Bras Med Esporte 2009;15(3):3-12. DOI: 10.1590/S151786922009000400001.

13. Braggion GF. Suplementação alimentar na atividade física e no esporte: aspectos legais na conduta do nutricionista. Nutrição Profissional 2008;4(17):40-50.

14. Domingues SF, Marins JCB. Utlização de recursos ergogênicos e suplementos alimentares por praticantes de musculação em Belo Horizonte/MG. Fit Perf J 2007;6(4):218-26.

15. Gomes RML. Consumo de suplementos alimentares em frequentadores de ginásio na Cidade de Coimbra. [Dissertação de Mestrado]. Faculdade de Medicina da Universidade de Coimbra; 2010.

16. De Rose EH, Feder MG, Pedroso PR, Guimarães AZ. Uso referido de medicamentos e suplementos alimentares nos atletas selecionados para controle de doping nos Jogos Sul-Americanos. Rev Bras Med Esporte 2006;12(5):239-42. DOI: 10.1590/S1517-86922006000500003.

17. Coelho CDF. Efeitos ergogênicos da suplementação de carnitina. [Monografia]. Faculdade de Medicina da UNESP/ Botucatu; 2002.

18. Pereira JMO, Cabral P. Avaliação dos conhecimentos básicos sobre nutrição de praticantes de musculação em uma academia da cidade de Recife. Rev Bras Nutrição Esportiva 2007;1(1):40-7.

19. Pereira RF, Lajolo FM, Hirschbruch MD. Consumo de suplementos por alunos de academias de ginástica em São Paulo. Rev Nutr 2003;16(3):265-72. DOI: 10.1590/S141552732003000300004.

20. Gualano B, Acquesta FM, Ugrinowitsch C, Tricoli V, Serrão JC, Lancha Junior AH. Efeitos da suplementação de creatina sobre força e hipertrofia muscular: atualizações. Rev Bras Med Esporte 2010;16(3):219-23. DOI: 10.1590/S151786922010000300013.

21. Santos MAA, Santos RP. Uso de suplementos alimentares como forma de melhorar a performance nos programas de atividade física em academias de ginástica. Rev Paul Educ Fís 2002;16(2):174-85.

22. Villegas García JA, Zamora Navarro S. Necesidades nutricionales en deportistas. Arch Med Deporte 1991;8(30):169-79.

23. Lemon WR. Effects of exercise on dietary protein requirements. Int J Sport Nutr 1998;8(4):426-47.

24. Ivy JL, Goforth HW Jr, Damon BM, McCauley TR, Parsons EC, Price TB. Early postexercise muscle glycogen recovery is enhanced with a carbohydrate-protein supplement. J Appl Physiol 2002;93(4):1337-44.

25. Borsheim E,Aarsland A, Wolfe RR. Effect of an amino acid, protein, and carbohydrate mixture on net muscle protein balance after resistance exercise. Int $\mathrm{J}$ sport Nutr Exerc metab. 2004;14(3):255-71.

26. Haraguchi FK, Abreu WC, Paula H. Proteínas do soro do leite: composição, propriedades nutricionais, aplicações no esporte e benefícios para a saúde humana. Rev Nutr 2006;19(4):479-88. DOI: $10.1590 /$ S1415-52732006000400007.

27. Hallak A, Fabrini S, Peluzio MCG. Avaliação do consumo de suplementos nutricionais em academias da zona sul de Belo Horizonte, MG, Brasil. Rev Bras Nutrição Esportiva 2012;1(2):55-60.

28. Quintiliano EL, Martins JCL. Consumo de suplemento alimentar por homens praticantes de musculação, nas academias centrais do município de Guarapuava/PR. Voos Revista Polidisciplinar Eletrônica da Faculdade Guairacá 2009;2:3-13.

29. Shneider C, Machado C, Laska SM, Liberali R. Consumo de Suplementos Nutricionais por Praticantes de Exercício Físico em Academias de Musculação de Balneário CamboriúSC. Rev Bras Nutrição Esportiva 2008;2(11):307-22.

30. Fernandes C, Gomes JM, Navarro F. Utilização de suplementos por praticantes de atividade física na cidade de São Paulo e região. Rev Bras Nutrição Esportiva 2012;3(13):5-12.

31. Andrade LA, Braz VG, Nunes APO, Velutto JN, Mendes RR. Consumo de suplementos alimentares por clientes de uma Clínica de Nutrição Esportiva de São Paulo. Rev Bras Ci e Mov 2012;20(3):27-36.

32. Araújo MF, Navarro F. Consumo de suplementos nutricionais por alunos de uma academia de ginástica, Linhares, Espírito Santo. Rev Bras Nutrição Esportiva 2012;2(8):46-54.

33. Hirschbruch MD, Fisberg M, Mochizuki L. Consumo de suplementos por jovens freqüentadores de academias de ginástica em São Paulo. Rev Bras Med Esporte 2008;14(6)539-43.

34. Hirschbruch MD, Carvalho JR. Nutrição esportiva: uma visão prática. Manole; 2002.

35. Espínola HHF, Andrade Costa MAR, Navarro F. Consumo de 
suplemento por usuário de academias de ginástica da cidade de João Pessoa-PB. Rev Bras Nutrição Esportiva 2008;2(7):1-10.

36. Fleischer B, Read M. Food supplement usage by adolescent males. Adolescence 1982;17(68):831-45

37. Dunn MS, Eddy JM, Wang MQ, Nagy S, Perko MA, Bartee RT. The influence of significant others on attitudes, subjective norms and intentions regarding dietary supplement use among adolescent athletes. Adolescence 2001;36(143):583-591.

38. Baylis A, Cameron-Smith D, Burke LM. Inadvertent Doping Through Supplement Use By Athletes: Assessment and Management. Int J Sport Nutr Exerc Metab 2001;11(3):365-83.

39. Lessa P, Oshita TAD, Valezzi M. Quando as mulheres invadem as salas de musculação: Aspectos biossociais da musculação e da nutrição para mulheres. Indicação Cientifica Censumar 2007;9(2):109-17.

40. Araújo ACM, Soares YNG. Perfil de utilização de repositores protéicos nas academias de Belém, Pará. Rev Nutr 1999;12(1):81-9.

41. Araújo LR, Andreolo J, Silva MS. Use of alimentary supplement and anabolizante for apprentices of muscular activity in the academies of Goiânia-GO. Rev Bras Ciên e Mov 2002;10(3): 13-8.

42. Jesus EV, Silva MDB. Suplemento alimentar como recurso ergogênico por praticantes de musculação em academias. In: Anais do III Encontro de educação Física e áreas afinsDepartamento de Educação física UFPI; 2008.

43. Fontes AMSA, Navarro F. Consumo de suplementos nutricionais por praticantes de atividade físicas em academias de Sete Lagoas-MG. Rev Bras Nutrição Esportiva 2012;4(24):515-23.

44. Krumbach CJ, Ellis DR, Driskell JA. A report of vitamin and mineral supplement use among university athletes in a division I institution. Int J Sport Nutr 1999;9(4):416-25.

45. Lehinger $A L$, Nelson $D L$, Cox MM. Princípios de bioquímica. 2. ed. São Paulo: Sarvier; 1995.

46. Miarka B, Luiz Junior CC, Interdonato GC, Del Vecchio FB. Características da suplementação alimentar por amostra representativa de acadêmicos da área de educação física. Mov \& Percep 2007;8(11):278-88.

47. Oliveira AAA, Santos PS. O consumo de proteína isolada da soja por praticantes de musculação. Rev Nutr Brasil 2007;6(4):217-21.

48. Reis MGA, Manzoni M, Simonard-Loureiro $H$. Avaliação do uso de suplementos nutricionais por freqüentadores de academias de ginástica em Curitiba. Rev Nutr Brasil 2006;5(5):56-61.

Como citar: FERREIRA, Alex Bisotto et al. Quais os suplementos alimentares mais utilizados?. Cinergis, Santa Cruz do Sul, v. 17, n. 1, mar. 2016. ISSN 2177-4005. Disponível em: <https://online.unisc.br/seer/index.php/cinergis/article/view/6909>. Acesso em: . doi:http://dx.doi.org/10.17058/cinergis.v17i1.6909. 